\title{
The hexane fraction of an Ardisia crispa ethanolic extract shows anti-arthritis effects in a rat arthritis model
}

\begin{abstract}
Ardisia crispa has been claimed by local villagers to have medicinal properties, and it is widely used in treating dysmenorrhea, rheumatism, orchitis, skin problem, coughs, fractured bones, sprains and treatment for women afterbirth [1]. To date, there is no report documented on Ardisia crispa's effect on chronic inflammation especially on anti-arthritic properties. The hexane fraction of an ethanolic extract of Ardisia crispa root (ACHE) was used in this study. Complete Freund's adjuvant (CFA) was injected onto plantar aponeurosis of right paw of rat to induce chronic arthritis. The following day onwards, ACHE at 3,10,30, and $100 \mathrm{mg} / \mathrm{kg}$ and also indomethacin as positive control were administered to the rats. Paw volume of rat was measured with a plethysmometer for 14 days. Ankle tissue was collected for ELISA test of tumor necrosis factor alpha (TNF- $\alpha$ ) and interleukin-1 beta (IL-1 $\beta)$. The result show that ACHE at all doses $(3.10 .30$ and $100 \mathrm{mg} / \mathrm{kg}$ ) have significant (p\&lt;0.05) inhibition of oedema by $45.3 \%, 64.31 \%, 73.12 \%$ and $49.55 \%$ respectively. At 3,10 and $30 \mathrm{mg} / \mathrm{kg}$, ACHE significantly reduced TNF- $\alpha$ by $45.2 \%, 45.7 \%$ and $25.1 \%$ respectively when compared with control. For IL- $1 \beta$, only $10 \mathrm{mg} / \mathrm{kg}$ and $30 \mathrm{mg} / \mathrm{kg}$ of ACHE elicited a significant (p\&lt;0.05) inhibition of this mediator in local tissue by $45.9 \%$ and $36.5 \%$ respectively. The efficacies of those doses were comparable to the effect of indomethacin (34.6\%). Thus, it can be concluded that Ardisia crispa posseses anti-arthritic effect on specific FCA-induced arthritis model in rats.
\end{abstract}

Keyword: Ardisia crispa; Anti-arthritic; CFA-induced arthritis 